\title{
Communication In Complex Information System Development Projects
}

\author{
Željko Hutinski, Neven Vrček, Goran Bubaš \\ University of Zagreb, Croatia \\ thutinsk@foi.hr mrcek@foi.hr and pbubas@foi.hm
}

\begin{abstract}
The relevance of the communication in the complex information system (IS) development projects is becoming issue of primary importance. Various researches show that many projects failed due to inadequate management of communication. Project data exchange is still not performed in a structured and standardised manner, which leads to misunderstandings between team members. Too many complex IS projects do not have established an adequate project communication management subsystems.

This paper analyses results of a survey performed on information technology (IT) professionals and presents degree of communication problems during various project phases. (This research was supported by the Croatian Ministry of Science and Technology under projects: "Strategic planning of Information Systems" and "Information Systems Security.) It reveals that average rating of a degree of communication problems varies at different project stages and among different communication subjects. The paper also proposes software tools that, if properly used, might enhance project communication. Such technologies are still not completely mature but they are developing fast and might play an important role in project management, by providing support to its holism.
\end{abstract}

Keywords: information system, development lifecycle, communication, groupware

\section{Introduction}

The issue of various communication aspects in information system development has been gaining a very significant role during last few years. In the modern project management theory, communication management (Dutoit, 1998) has been viewed as an essential element during various stages of project lifecycle. This is especially true regarding Internet as a global network, which interconnects team members in dynamic and geographically distributed environment. Nowadays we have teams that are not physically present at one place but share common problems in their efforts to develop a certain software product within given constraints.

Material published as part of this proceedings, either on-line or in print, is copyrighted by the author with permission granted to the publisher of Informing Science for this printing. Permission to make digital or paper copy of part or all of these works for personal or classroom use is granted without fee provided that the copies are not made or distributed for profit or commercial advantage AND that copies 1) bear this notice in full and 2) give the full citation on the first page. It is permissible to abstract these works so long as credit is given. To copy in all other cases or to republish or to post on a server or to redistribute to lists requires specific permission from the author.
In such a point of view communication management has different aspects. It has to deal with various communication skills, which have to be established and constantly refined in order to achieve team coherence. Team communication knowledge must include: trust development skills (Bandow, 1998), teamwork skills (Nath, 1996), human facilitator skills (Beise, 1992), change agentry skills (Markus, 1996), and emancipatory skills.

In distributed teams these skills are equally important but teams are dispersed and we must have appropriate tools to support all kinds of communication skills. Electronic mail is certainly a very precious way of exchanging data, messages and information between team members but we need more specialised and sophisticated tools that are capable to store and structure the data of the project.

Our research deals with level of communication problems that might be expected during various stages of IS and software development. On the basis of the obtained results we evaluate software tools for project communication management. 


\section{Information System Development Project Lifecycle}

There are several stages during software development lifecycle. However we still do not have a standardized and unified approach to their definition and demarcation of interstage boundaries. Quite generally we can say that we have (Avison, 1997): feasibility study, system investigation, system analysis, system design, implementation, and review and maintenance. However for the research on communication problems this distinction is too coarsely grained and therefore we used it as a starting point but developed more diverse classes of IS development lifecycle:

- conceptualising the preliminary proposal of the IS or software application(s);

- identifying specific requirements;

- preparing the presentation of the offer/concept;

- presenting the offer/concept of the IS or software applications;

- definition of the software development project plan;

- team member definition and task distribution;

- work on design and coding;

- optimisation of the prototype IS or software application(s);

- testing at the site of the client/user;

- implementing at the site of the client/user.

In these stages we have a variety of communication issues. They might be directed to users or arise within project team.

\section{Materials And Methods}

The aim of this research is to evaluate intensity and significance of communication problems that arise during various stages of IS development lifecycle. In research we used a questionnaire that contained 16 questions. 6 of them were demographic and 10 were used to determine intensity of communication problems that appeared during established project phases. The rating was performed on a 0-5 point Lickert type scale ranging from no problems/insignificant difficulties (i.e. "0") to great problems/notable difficulties (i.e. "5"). Research was performed on 227 IT professionals. They all had significant experience and were engaged in complex IS development projects in which they were responsible for various disciplines: software engineering, IS design, presentation (selling), and project team management. On the average they had 9 years of work experience.

Collected data were systemised and analysed by standard statistical methods and exploratory factor analysis (principal components with Varimax rotation).

\section{Results And Discussion}

For the purpose of this paper we extracted three groups of research results. The first group presents communication problems that appeared during IS development and their causes. Basic analysis was performed to determine nature and intensity of communication problems. These problems were analysed through ten stages of IS development cycle (See Figure 1).

Our analysis shows that the majority of communication problems arise during identifying specific requirements phase. This stage requires intensive communication within 


\section{Communication in Complex Information System Development Projects}

various subjects in order to strictly determine required program characteristics.

The second level of communication problems intensity appears during implementation at the site of the client/user. Beside that we have other phases with lower intensity levels.

The second group of results presents the factor analysis of communication problems structure during IS development. When exploratory factor analysis was performed on the ratings data in order to investigate the structure of communication problems in IS and software application development, three factors were found that together explained $57 \%$ of the variance (each factor had eigenvalue greater than 1.0 and explained more than $10 \%$ of the variance). The uncovered factor structure is displayed in Table 1. Even though this structure is not fully transparent, it does outline the three most general phases in the composition of communication problems associated with
IS and software development, i.e. the proposalrequirements-selling phase $(F 1)$, the organizing-designcoding or production phase (F2), and the optimizationtesting-implementing phase $(F 3)$. It must also be emphasized that considerable projections of variables related to preparing the presentation and presenting the offer and the variable team member definition and task distribution on the third factor named implementing (F3), as displayed in Figure 1, could indicate that problems unresolved in the previous communication segments could negatively reflect on the interaction in this final phase in the structure of communication during IS and software development.

The third group of presented results is constituted from detailed analysis of communication problems during IS development. After determination of communication complexity of certain phase, experts were asked to precisely determine causes of communication problem.

\begin{tabular}{|c|c|c|c|}
\hline & $\begin{array}{c}\text { F1 } \\
\text { requirements }\end{array}$ & $\begin{array}{c}\text { F2 } \\
\text { production }\end{array}$ & $\begin{array}{c}\mathrm{F3} \\
\underset{\mathrm{g}}{\text { implementin }}\end{array}$ \\
\hline Conceptualizing the preliminary proposal & .67 & - & - \\
\hline Identifying specific requirements & .73 & - & - \\
\hline Preparing the presentation of the offer & .63 & - & .43 \\
\hline Presenting the offer to the client / user & .48 & - & .58 \\
\hline Definition of the project plan & - & .67 & - \\
\hline $\begin{array}{l}\text { Team member definition and task } \\
\text { distribution }\end{array}$ & - & .59 & .37 \\
\hline Work on design and coding & - & .82 & - \\
\hline Optimization of prototype application(s) & - & - & .79 \\
\hline Testing at the site of the client / user & - & - & .66 \\
\hline $\begin{array}{l}\text { Implementation at the site of the client / } \\
\text { user }\end{array}$ & - & .34 & .67 \\
\hline
\end{tabular}

Table 1: Results of exploratory factor analysis of the ratings of communication problems in different segments of communication during IS and software development (projections of variables that are most representative for each factor are written in boldface;values below 0.30 are not presented). 


\section{Hutinski, Vrček, Bubaš}

Conceptualizing the preliminary proposal, achieved relatively high level of communication complexity. The main reason for this was found in end-users inability to specify requirements. This is due to their lack of knowledge but also to their resistance to change their current work practice. Users also think that IT experts use too many technical terms without focusing on business domain issues.

Identifying specific requirements. More than $50 \%$ of the respondents rated difficulties in communication at this stage from moderate to great / notable (i.e. in the range from 3 to 5 on a 0-5 point scale). Responses regarding the causes of difficulties were predominantly related to deficiencies in problem definition like imprecision, incompleteness, misunderstanding, inferior problem assessment, unclear goals, and unawareness of complete necessities: in this phase both the clients/users and IT experts were involved. Other significant causes of difficulties were related to the already mentioned lack of IT knowledge and resistance to change on behalf of clients/users, as well as to the lack of domain knowledge of IT professionals.

Preparing the presentation of the offer. This phase was rated with relatively low level of communication complexity. The causes of communication problems were also described quite differently. However, most of them were related to the business presentation aspect of communication as, for instance, the possibility of not achieving a satisfactory clarity and comprehensiveness, an inadequate selection of presentation content, an inappropriate partition of time used for oral presentation versus software demonstration, deficiency in adaptation to the audience profile etc. The difficulties were also related to obstacles connected with client/user resistance to change, lack of IT knowledge, and inadequate problem definition.

Presenting the offer / concept of the IS or software application(s). The fairly low degree of difficulty at this point in communication during IS and software development is perhaps associated with the common atmosphere of presentational communication that is characterized by formality and conciseness. Still, problem is caused by different levels of detail in the presentation of the system that is wanted by various representatives of clients / users. The insufficiency of simple persuasive efforts combined with the disproportionate technical elaboration were another source of difficulty, as well as a poor adaptation to the IT knowledge level of clients / users.
Definition of the software development project plan. Slightly more than $1 / 3$ of the respondents rated the difficulties in communication at this point from moderate to great / notable (i.e. in the range from 3 to 5 on a 0-5 point scale). Therefore, this segment in communication during IS and software development could be considered as having a moderate degree of communication problem. The identified causes of difficulties were mostly associated with shortage of time and, especially, with problems concerning deadlines, which were either unreasonable, indecisively set, disregarded, or not negotiable.

Furthermore, problems were associated with insufficient assessment and lack of information about the needs of clients / users or deficits in requirements specification, along with unclear vision of the integrated system as a whole. Conceptual differences among team members were also noticed as a source of problem, as well as deficiency of team members either in number or qualification.

Team member definition and task distribution. This was the point with the least average difficulty in communication during IS and software development. The predominant causes of potential problems were related to the shortage of IS and software experts and also to their work overload, particularly of those with greater expertise. Other problems were associated with managers who had insufficient insight into competencies of individual IT workers, as well as with their inclination towards inadequate task distribution that overlooked individual specialization, interest, affinity, and availability of team members. Additional problems were connected with a lack of problem domain specialists and difficulties in coordinating / organizing people and tasks.

Work on design and coding. This stage received a somewhat lower degree of the average estimate of difficulty in communication. The predominant problem was related to deadlines that were either set too close, inadequately estimated, or uncoordinated. Other communication problems were associated with improperly defined tasks and objectives. Dissonance among team members, confrontation over different concepts, inadequate interpersonal relations, lack of team spirit, and deficient team communication were also noted as sources of communication problems. Finally, supplements to original design once the coding process has started, as well as incompatibility of different programmed modules were mentioned as well.

Optimization of the prototype IS or software application(s). A rather low degree of average estimate of communication problems was found also at this stage. The existing difficulties were caused mostly by noncompliance with deadlines, delays in software completion, and lack of time. 
Other sources of difficulty were related to additional requests for changes in requirements specification (sometimes at the last moment), vagueness in project definition, disorganized and insufficiently specified (sometimes unreasonable) demands from clients / users, and also to lack of cooperation and poor feedback from clients / users.

Testing at the site of the client / user. This stage in communication during IS and software development had a moderately high average rating of communication difficulty. The causes of problems were predominantly associated with resistance to change and novel IT technology, as well as with unsatisfactory IT related knowledge and skill of clients / users. Inadequate or insufficient test data for evaluation of the system, as well as lack of time to perform the testing were also identified as causes of difficulty. Poorly defined requests, additional requirements, unreasonable expectations, deficient cooperation, contrasting "tastes" for various features of the user interface, and different interpretations of earlier agreements were specified as further sources of communication problems between IT specialists and clients / users.

Implementing at the site of the client / user. Rather high average rating of communication difficulty was found at this conclusive point of communication during IS and software development. In fact, about $45 \%$ of the respondents rated the difficulties in communication at this stage from moderate to great / notable (i.e. in the range from 3 to 5 on a 0-5 point scale). Most communication problems concerning the implementation process were caused by resistance to change and fear of IT, together with lack of familiarity with IT that negatively affects its utilization, and ineffective participation of clients / users in training that is performed to facilitate adoption of IT.

Conclusions based on the presented results show that communication problems are very complex issues that arise during IS development cycle. Although there are many reasons why they appear the majority of misunderstandings come from a relatively low level of knowledge of end-users and from their reluctance to accept new ways of work due to introduction of modern technologies. IT specialists are very much affected by communication problems because they directly influence product functionality, project schedule, etc.

\section{Improvement Of Project Management Communication}

In our research, we additionally tested several software tools which might improve communication during IS development projects. These are so called teamware and groupware packages (Cox, 1998), and are entering the arena of large scale, IS projects. Their main purpose is to enhance information interchange between participants during a project. Since this was a laboratory experiment we do not have relevant statistical indicators through which we might correlate the software tool features with investigated communication problems. Introduction of such tool in project team is a very significant change and teams are reluctant to accept such a fast adoption of new project standards. However we were able to deliver certain conclusions because we could monitor on which parts of software development lifecycle was each of these packages best suited. We tested 4 such packages (Dušak, 1999):

- Instant TeamRoom - Lotus Inc.,

- QuickPlace - Lotus Inc.,

- TeamWARE Office 5.1 - Fujitsu Software Corp and

- eRoom - Instinctive Technology.

We performed intensive comparative study in each of the IS project development lifecycle according to several criteria:

- Communication inside project team:

- Document exchange and version tracebility,

- Project planning,

- Project state reporting.

- Communication between subprojects and project phases

- Configuration management

- Projects results checking

- Quality management

- Communication between project and its environment

- Tracing and correction of projects results

- Risk management

- Validation of projects results

Our results show that reviewed program packages exhibit best performance in the areas of communication inside project team, with very good support for document interchange and version tracebility. The communication between subprojects and project phases and communication between the project and its environment is not supported at the adequate level. In these areas their support is partial and therefore features of different software tools have to be combined to achieve a higher performance. 
Significant problems also arise in communication with end users. They should be involved to take part in such a formalised data interchange without human interaction. However, their technological level (both from knowledge and technical perspective) is usually not adequate to be included in teamware environment. Our results reveal that in this area we still must have a significant amount of direct ("eye to eye") contacts to achieve a satisfactory level of mutual understanding. We also think that with addition of multimedial features (teleconferencing, video, audio) teamware packages might achieve a higher level of acceptance with the end users and might become valuable tools in communication of IT professionals with end user during project development.

\section{Conclusion}

In this paper we presented results of an ongoing research about intensity and nature of communication problems that arise during complex IS development projects. The analysed results show that the project management in software industry is facing serious communication problems, due to various reasons. However, the most serious ones of them are related to end users who still have problems in understanding IT specialists. Such misunderstandings might have serious impacts on project outcome. Therefore each interaction with end user should be performed in their business domain vocabulary because they want solution for their problems and mostly do not pay much attention to technological issues. However there are situations in which end users deliberately reject new IT solutions, and the communication misunderstandings are their easiest way to avoid the real problems. In such situations the project management should use a more formalized communication approach in order to lead the project in desired direction.

The software tools for the project team communication are quite helpful, but in many cases they do not achieve the desired results, especially the ones of the end users. They require a certain level of technical and project management knowledge, which might be too specific and complex for inexperienced users. However, these tools are going to play a significant role in the future because of their ability to preserve knowledge of previous projects and a structured approach to project communication.

\section{References}

Avison, D.E., \& Shah, H.U. (1997) The Information Systems Development Lifecycle: A First Course in Information Systems. London, UK: McGraw-Hill.

Bandow, D. (1998, March) Working with the Borg: Trust development and dispersed work groups. Proceedings of the 1998 Conference on Computer Personell Research, 163-169,

Beise, C.M., Niederman, F., Beranek P.M.. (1992, April) Facilitatying technology supported group work: A new category of IS personnel. Proceeding of the 1992 ACM SIGCPR Conference on Computer Personnel Research, Cincinnati, OH, USA, 250-258.

Cox, N. (1998) Web-based teamware lets users work in concert. Network Computing, vol 9, 102-103.

Dutoit, A.H.; Bruegge, B. (1998) Communication Metrics for Software Development. IEEE Trans. on Software Engineering, vol. 24, 615628.

Dušak, V., Vrček, N. (1999) Information Technology as a Prerequisite of Successful Project Communication., Informatologija, vol. 32, 173-179.

Markus, M.L., Benjamin, R.I.. (1996) Change agentry: The next IS Frontier. MIS Quarterly, vol. 20(4), 385-407.

Nath, R., Lederer, A.L. (1996) Team building for IS success. Information Systems Management, vol. 13, 32-37.

\section{Biographies}

Željko Hutinski is Professor at Faculty of Organisation and Informatics in Varaždin, University of Zagreb, Croatia. His area of interest is information systems development and project management.

Neven Vrček is Assistant Professor at Faculty of Organisation and Informatics in Varaždin, University of Zagreb, Croatia. His area of interest is e-commerce and he is author of several papers on this subject.

Goran Bubaš is Assistant at Faculty of Organisation and Informatics in Varaždin, University of Zagreb, Croatia. He is author of several papers regarding communication issues in software development. 